\title{
Adaptação dos estudantes universitários em tempo de pandemia enquanto
}

\section{isolamento social}

Adaptation of university students in time of a pandemic as social isolation

Adaptación de estudiantes universitarios en tiempos de pandemia como aislamiento social

Recebido: 30/11/2021 | Revisado: 05/12/2021 | Aceito: 10/12/2021 | Publicado: 18/12/2021

Cláudio Luiz Chiusoli

ORCID: https://orcid.org/0000-0002-7844-3632

Universidade Estadual do Centro Oeste, Brasil E-mail: prof.claudio.unicentro@gmail.com

Julie Cristini Dias

ORCID: https://orcid.org/0000-0002-8412-0063

Universidade Estadual do Centro Oeste, Brasil E-mail: julie.cris.dias@gmail.com

Lucas da Costa

ORCID: https://orcid.org/0000-0001-5687-0898

Universidade Estadual do Centro Oeste, Brasil E-mail: lucascostaa177@gmail.com

Lucas Serbai

ORCID: https://orcid.org/0000-0002-1158-5636

Universidade Estadual do Centro Oeste, Brasil E-mail: lucas.serbai01@gmail.com

\begin{abstract}
Resumo
O objetivo do estudo foi analisar o comportamento de consumo, hábito e atitudes dos estudantes universitários durante o lockdown em relação a pandemia da COVID-19. Considera-se um estudo exploratório e quantitativo. Quanto a amostragem, foi utilizada a não-probabilística por conveniência em um total de 100 entrevistas, em uma instituição pública e privada em uma cidade do interior do Paraná. Os principais achados foi que entre os entrevistados, 90,4\% concordam que é importante conhecer o procedimento de higienização dos produtos alimentícios; $85,6 \%$ concordam que uma empresa que oferece delivery faz com que comprem mais; $75,0 \%$ perceberam que com o isolamento as propagandas de produtos aumentaram; 70,2\% procuram sempre comprar marcas adquiridas anteriormente; $72,1 \%$ concordam que passaram a comprar menos em lojas físicas, e que por outro lado $64,4 \%$ passaram a comprar mais em lojas on line. Cerca de 42,3\% concordam que durante a pandemia, a confiabilidade quanto a higiene de lanchonetes/fastfood diminuiu e apenas $25 \%$ concordam que com isolamento social compras de bens não-essenciais estão mais frequentes. Foi identificado que as compras on line aumentaram devido ao cenário atual, que não deixaram de comprar, mas sim migraram mais para compras on line pela facilidade e praticidade, fazendo assim que o comércio eletrônico continue com seu fluxo de venda de produtos e demonstraram ainda que se preocupam com a higiene e qualidade dos produtos alimentícios quando adquiridos.
\end{abstract}

Palavras-chave: Compras on line; Pandemia; Estudantes universitários.

\begin{abstract}
The Study objective is to analyze the consumption behavior, habits and attitudes of university students during the lockdown in relation to the COVID-19 pandemic. It is considered an exploratory and quantitative study. As for the sampling, the non-probabilistic for convenience was used in a total of 100 interviews, in a public and private institution in a city of Paraná interior. The main findings were that among the interviewees, $90.4 \%$ agreed that it is important to know the procedure for cleaning food products; $85.6 \%$ agree that a company that offers delivery makes them buy more; $75.0 \%$ realized that with isolation, product advertisements increased; $70.2 \%$ always seek to buy previously acquired brands; $72.1 \%$ agree that they started to buy less in physical stores, and that, on the other hand, $64.4 \%$ started to buy more in online stores. About $42.3 \%$ agree that during the pandemic, the reliability of cafeteria/fast food hygiene decreased and only $25 \%$ agree that with social isolation, purchases of non-essential goods are more frequent. It was identified that online shopping increased due to the current scenario, which did not stop buying, but migrated more to online shopping due to the ease and practicality, thus making e-commerce continue with its flow of product sales and they demonstrated even though they are concerned with the hygiene and quality of food products when purchased.
\end{abstract}

Keywords: Online shopping; Pandemic, College students. 


\begin{abstract}
Resumen
El objetivo del estudio fue analizar el comportamiento, hábitos y actitudes de consumo de los estudiantes universitarios el encierro en relación a la pandemia COVID-19. Se considera un estudio exploratorio y cuantitativo. En cuanto al muestreo, se utilizó la conveniencia no probabilística en un total de 100 entrevistas, en una institución pública y privada de una ciudad del interior de Paraná. Los principales hallazgos fueron que entre los entrevistados, el 90,4\% coincidió en que es importante conocer el procedimiento de higiene de los productos alimenticios; El 85,6\% está de acuerdo en que una empresa que delivery les hace comprar más; El 75,0\% se dio cuenta de que con el aislamiento aumentaba la publicidad de productos; El 70,2\% siempre busca comprar marcas previamente adquiridas; El 72,1\% coincide en que empezó a comprar menos en las tiendas físicas y que, en cambio, el 64,4\% empezó a comprar más en las tiendas online. Alrededor del 42,3\% está de acuerdo en que durante la pandemia, la confiabilidad de la higiene de la cafetería / comida rápida disminuyó y solo el $25 \%$ está de acuerdo en que con el aislamiento social, las compras de bienes no esenciales son más frecuentes. Se identificó que las compras online se incrementaron por el escenario actual, el cual no dejó de comprar, sino que migró más a las compras online por la facilidad y conveniencia, permitiendo así que el comercio electrónico continúe con su flujo de venta de productos y también demostraron que preocuparse por la higiene y la calidad de los productos alimenticios cuando se compran.
\end{abstract}

Palabras clave: Compras en línea; Pandemia; Estudiantes universitarios.

\title{
1. Introdução
}

Mundialmente, a pandemia da COVID-19 excede aos indicadores de saúde pública manifestando seus graves efeitos em indicadores socioeconômicos (Avelar et al, 2020; IPEA, 2020). No Brasil, o Instituto de Pesquisa Econômica Aplicada (IPEA, 2020), aponta algumas características preliminares sobre a crise gerada, sendo: a) desalinhamento grave no mercado entre demanda [raramente frequente] e oferta, b) atividade econômica brasileira com resultado negativo de - 6,4\%, segundo o Banco Central do Brasil (BCB), c) previsão de comportamento da economia brasileira de - 9,1\% conforme Fundo Monetário Internacional (FMI) o que equivale à depressão econômica profunda, d) mercado de trabalho com redução no número de ocupados com, no mínimo, 4,9 milhões de postos de trabalho encerrados segundo a Pesquisa Nacional por Amostragem de Domicílio (PNAD) de 2020, e) menor Indicador de Incerteza da Economia Brasil já registrado nos últimos vinte anos, conforme Instituto Brasileiro de Economia (IBRE) da Fundação Getúlio Vargas (FGV), e f) aumento da dívida bruta do governo geral de $75,8 \%$ para $93,7 \%$.

Mesmo diante deste cenário, as empresas buscaram por inovações e aperfeiçoamento para evitar a falência ou ter prejuízos devastadores em momentos difíceis quando o gestor precisa ter uma melhor decisão empresarial junto ao mercado e com seus subordinados buscando conhecimentos e técnicas para manter a sua vida financeira "saudável”. Assim, a produção e a entrega das mercadorias ao cliente tornaram-se uma situação importante a ser estudada, visto que devido à restrição do consumo no local, os deliveries de produtos aumentaram substancialmente (Lanchimba et al, 2020).

Apesar do enfrentamento de instabilidade financeira, o mercado tende a forçar as empresas para que se especializem em meios digitais como sendo suas prioridades, visto que em época de pandemia, o distanciamento social torna-se comum e as empresas entender o mercado e suas estratégias, afim de competir nesse novo ambiente e buscar os consumidores imersos na cultura digital, uma vez que as organizações precisam manter sua reputação (Feitosa \& Garcia, 2016).

Considerando o grupo de estudantes universitários, por se tratar da geração que está muito conectada é o desejo das organizações entender seu comportamento de consumo e com isso é necessário que o gestor seja consciente e tenha capacidade de planejar um novo método de desenvolvimento das tarefas para que o fluxo da produção não pare atenda esse perfil de consumidor (Oliveira Rosa et al., 2017).

Pensando nisso, as mudanças e adaptação de consumo durante o momento pandêmico, caracterizam o seguinte problema de pesquisa: qual o comportamento de consumo, hábito e atitudes dos estudantes universitários durante o lockdown em momento de isolamento social em relação a pandemia da COVID-19?

O objetivo é analisar o comportamento de consumo, hábito e atitudes dos estudantes universitários durante o lockdown em momento de isolamento social em relação a pandemia da COVID-19. 
Isto considerando, dificuldades enfrentadas pelas empresas para se adaptar à pandemia, trazendo um grande risco à saúde financeira da mesma e à organização em seus setores de produção. Assim, o presente relato de pesquisa justifica-se pelo fato que é importante o gestor conhecer os hábitos de compras do grupo de estudantes universitários e que as inovações e adaptações são necessárias em tempos de pandemia, mais concretamente, são as decisões que devem tomar em momento tão conturbado, como um corte de custos, entrega de mercadorias e quais métodos de trabalho devem ser utilizados para que consigam continuar faturando em época de crise.

Como objetivos específicos, pretende-se identificar se: i) passaram a comprar menos em lojas físicas; ii) passaram a comprar mais lojas on line; iii) durante o isolamento social passou a comprar mais bens não-essenciais; iv) se interessa em comprar mais em uma empresa que oferece delivery; v) com o isolamento perceberam aumento das propagandas de produtos; vi) durante a pandemia, diminuiu a confiabilidade sob higiene de lanchonetes/fastfood; vii) consideram importante conhecer o procedimento de higienização dos produtos alimentícios antes de comprar; e viii) procuram sempre comprar marcas que eram adquiridas anteriormente.

\section{Referencial Teórico}

O lockdown que se trata de bloqueio total de uma região, imposta pelo Estado ou pela Justiça, como medida mais rígida adotada durante situações extremas, no caso, a pandemia. A restrição ao cidadão é total no sentido circular em áreas públicas sem motivos emergenciais, cruzar fronteiras e muitas vezes pode haver toque de recolher e a fiscalização é feita pelo Governo.

Com isso, o enfrentamento da COVID-19, foi intensificado, possibilitando que todos os Estados adotassem distintas medidas restritivas de direitos e liberdades públicas, a depender do avanço da doença na respectiva área geográfica (Alves et al., 2020).

Bueno Neto et al (2020) ressalta que, China, Taiwan, Cingapura e Coréia do Sul foram além do "lockdown" e combinaram profissionais/estruturas da saúde/domicílio do paciente, comunidade, testagens, rastreamento e monitoramento por tecnologia da informação ( $Q R C o d e$ ) fundamentados a partir de experiências de outras contaminações respiratórias graves vividas nestes Países. Logo, comprovaram que a combinação destes recursos reduz a contaminação pela COVID-19.

Como a prática do isolamento social tem causado muitas polêmicas no País, algumas autoridades mostram-se céticas quanto à sua eficácia, mas o fato é que boa parte dos gestores públicos optaram por adotar de medidas como estratégias de controle da mobilidade dos cidadãos, como o fechamento de escolas e universidades, do comércio não essencial, e de áreas públicas de lazer, entre outros (Bezerra et al, 2020).

E uma vez imposta esta situação, as empresas precisaram se organizar e segundo Vasconcelos e Vasconcelos (2020), a importância de se prepararem e planejarem durante os períodos de crise para o futuro incerto é fator fundamental em períodos de crise e principalmente, após a crise. Crise esta, que já foi vultuosa no primeiro trimestre/2020 nas empresas brasileiras de capital aberto.

Operacionalmente, cada empresa teve redução do valor de $\mathrm{R} \$ 4,1$ bilhões durante fevereiro/2020 tendo como efeitos causais a incerteza nas previsões, queda na demanda e inadimplência, proibição de funcionamento e desvalorização cambial. Queda de receitas, aumento de ciclos operacional e financeiro, rentabilidade das empresas, aumento do endividamento da estrutura de capital são indicadores de desempenho econômico-financeiros mais afetados negativamente no referido trimestre. Somente os indicadores econômico-financeiros de liquidez mantiveram-se próximos aos indicadores do período anterior. $\mathrm{Na}$ captação de empréstimos e financiamentos a tangibilidade está sendo mitigadora de riscos para estas empresas (Avelar et al, 2020). 
O desafio é aterrador, mas, na busca por um "oceano azul" com o uso de inovação e estratégia de negócio transforma a organização em uma empresa vencedora e melhor preparada para períodos de grande incerteza econômica, social e sanitária. Logo, torna-se fundamental uma empresa se preparar para enfrentar qualquer tipo de situação, mantendo uma saúde financeira e com métodos de trabalho que venham a continuar atendendo ao público de forma segura e correta.

Para que assim, sejam bem sucedidas no mercado competitivo e ganhar confiança do consumidor superando a concorrência e gerando valor significativo na entrega compreendendo os reais desejos e necessidades dos consumidores (Kotler \& Armstrong, 2015).

Nessa situação o consumidor influenciou-se por vários aspectos culturais, econômicos, sociais e psicológicos que estão relacionados e inseridos aos grupos de convivências e durante esse momento de lockdown, essa característica torna-se marcante para determinar suas preferências e desejos de consumo de determinada marca (Oliveira Rosa et al., 2017).

Reside aqui, os grandes obstáculos desafiadores do empreendedor, pois se a sustentabilidade econômico-financeira das empresas de capital aberto abalou-se já no primeiro trimestre da pandemia da COVID-19 no Brasil (Avelar et al, 2020, p. 8-13) entre os micro empreendedores o impacto é devastador e imensurável porque não tem uma estrutura organizacional formatada como as empresas maiores. Tradicionalmente, o microempreendedor tem dificuldade de crédito para capital de giro e investimento.

Melito (2020), reitera em entrevista a Montella, que o problema do empreendedor brasileiro não está só no acesso ao crédito. As soluções precisam atender a outras demandas do empreendedor com auxílio, orientação e formação que capacitem os micros, pequenos e médios empresários. Não adianta nada o mercado ter taxa de juros compatíveis, garantias e ser rápido no crédito, se a capacidade de gestão está ruim. Ele vai ter o dinheiro, mas não vai ter condições de enfrentar as adversidades do mercado.

É neste momento de escolha (trade-off) que os gestores de pequenas empresas abandonam suas crenças, sejam elas raízes de seus sucessos passados e desenvolvem novas habilidades e atitudes, situação exigente para um estrategista (Mintzberg et al., 2010).

Como estrategista o empreendedor utiliza-se da estratégia emergente principalmente, para as adversidades de mercado. Rodrigues (2016) salienta que, a estratégia emergente é essencialmente reativa, nascendo das respostas e ameaças competitivas, onde a rapidez de adequação das mesmas irá sustentar a agilidade competitiva, tal como a que o mundo enfrenta com a COVID19 nos dias atuais. A internet vem sendo uma das estratégias emergentes definidas para o enfrentamento do contexto que a COVID-19 gera para as empresas.

Osborn (1998, apud Rodrigues, 2016), afirma que a essência das estratégias emergentes é reativa. Logo, ameaças repentinas de diversas naturezas fazem com que aconteçam reações das empresas por meio de estratégias emergentes. Para Gimenez (1998), reações impulsivas a eventos do ambiente caracterizam a essência reativa da estratégia configurando-se quase como uma "não-estratégia".

Diante de um melhor acesso e disponibilidade da internet e da WEB 2.0, diversos canais de comercialização, além do próprio site das empresas, se apresentaram como alternativas integradas ao ecommerce, como google adWords, e-mail marketing e facebook no aspecto de prospecção de clientes (Maia et al., 2019).

Muitos negócios que já possuíam sites, no entanto estes eram inicialmente de informação e propaganda, mas tiveram que ser readequados para suportar as vendas virtuais e para Maia et al. (2019) as empresas business-to-business (B2B) estão se adaptando com muito esforço a este novo cenário.

A internet e canais de comunicação eram vistos como meios informativos com os clientes, sobretudo pelo fato das compras nesse mercado serem muitas vezes individualizadas e as negociações serem específicas para cada comprador e fornecedor business-to-consumer (B2C). Assim o comércio eletrônico, até pela situação do isolamento, permitiu um maior 
intercâmbio, de compra e venda de produtos e serviços pelas plataformas eletrônicas devido à crescente demanda verificada (Chiusoli \& Bonfim, 2020). Pelo visto, nota-se que a internet é a estratégia emergente mais aplicada pelas empresas no enfrentamento à pandemia da COVID-19.

\section{Metodologia}

Este estudo foi realizado por meio de uma revisão bibliográfica que, de acordo com Gil (2017), é elaborada baseada em temas publicados em livros, artigos científicos e outras publicações. Quanto à natureza das variáveis, o método utilizado foi quantitativo, que quantifica as opiniões, dados, na forma de coleta de informações, assim também como um emprego e cursos e técnicas estatísticas como porcentagem média e mediana (Aaker et al., 2001). Quanto ao objetivo, considera-se um estudo exploratório que segundo Marconi e Lakatos (2017), foi pelo fato que o pesquisador pode se aprimorar mais sobre o assunto e explorar a pesquisa para conhecimentos mais específicos diante do tema abordado, sendo assim que o mesmo possa retirar informações mais concretas e que hipóteses sejam formuladas, para a realização do trabalho.

A população e unidade de observação deste estudo constituíram-se de estudantes universitários e em relação à técnica de amostragem, foi utilizada a não-probabilística por conveniência em um total de 100 (cem) estudantes universitários, de uma instituição de ensino superior pública e de uma instituição de ensino superior privada situadas em uma cidade do interior do Estado do Paraná cuja instituições recebem esses grupos de estudantes da região.

De acordo com Gil (2017), a classificação da amostragem como não-probabilística é devida aquela que não apresenta fundamentação probabilística, dependendo unicamente de critérios do pesquisador.

Foram 10 (dez) as variáveis investigadas, sendo 02 (dois) perfis - gênero e faixa etária - essas questões abordavam sobre: compras em lojas físicas, compras em lojas on line, compras de bens não-essenciais, compras em uma empresa que oferece delivery, percepção de aumento das propagandas de produtos, diminuição da confiabilidade da higiene em lanchonetes/fastfood, importância de conhecer o procedimento de higienização dos produtos alimentícios antes de comprar e compras de marcas adquiridas anteriormente.

Quanto as escalas utilizadas a ordinal predominaram mediante escala de 03 (três) pontos concordo/indiferente/discordo; sendo que, a escala ordinal é obtida pela classificação dos objetivos ordenados em função de alguma variável em comum (Aaker et al., 2001).

Quanto à forma da coleta dos dados e abordagem, trabalhou-se por meio de levantamento mediante entrevistas on line, mediante envio de questionários eletrônicos, por meio do google forms para o grupo de estudantes universitários das instituições pesquisadas com sede na mesma cidade pesquisada.

Quanto à procedência dos dados, foram utilizados dados primários, pois são informações coletadas para o propósito da questão (Kotler \& Armstrong, 2015). Quanto ao recorte, é feito um recorte transversal, que se tratou de uma pesquisa feita em um momento em específico e uma única vez (Flick, 2012).

Quanto à técnica estatística, a análise dos dados consistiu-se em análises univariadas e bivariadas com base em frequências absolutas e relativas e processadas por meio do SPSS (Statistical Package for the Social Sciences). As medidas de associação foram testadas por meio do teste não-paramétrico Qui-Quadrado (Siegel \& Castellan, 2017). O teste é uma estatística utilizada que avalia se as observações não pareadas entre duas variáveis são independentes entre si, sendo aplicadas ao nível de significância de 5\%, para testar se deve ou não rejeitar as hipóteses postuladas.

Assim, se o $p$-valor obtido for abaixo de 5\% ( $p \leq 0,05)$, as variáveis são independentes e as hipóteses devem ser rejeitadas; caso contrário, se for acima de 5\%, não devem ser rejeitadas (Siegel \& Castellan, 2017). 
Ou seja, o Teste Qui-Quadrado foi utilizado para analisar a existência da relação das variáveis investigadas entre estudantes universitários considerando gênero e faixa etária.

Contido essas informações, as hipóteses da pesquisa foram:

- H0: não há diferença significativa na opinião dos participantes em relação as variáveis pesquisadas segmentadas por gênero (masculino e feminino); e

- H1: não há diferença significativa na opinião dos participantes em relação as variáveis pesquisadas segmentadas por faixa etária (até 19 anos, de 20 a 25 anos e acima de 25 anos).

\section{Resultados e Discussão}

Nessa seção, é apresentada análise e discussão dos resultados, sendo composta por 09 (nove) tabelas. As Tabelas de 1 a 8, referem-se aos objetivos propostos segmentados por gênero e faixa etária considerando o comportamento de compra e consumo dos estudantes universitários participantes do estudo. Por fim, a Tabela 9 apresenta os resultados do Teste QuiQuadrado resumidamente, mostrando se há rejeição ou não das hipóteses H0 e H1 investigadas.

O perfil dos pesquisados quanto à faixa etária indica que 17,3\% possuem até 19 anos, $48,1 \%$ são de 20 a 25 anos e $34,6 \%$ acima de 26 anos. Quanto ao perfil por gênero ligeiramente, predominam as mulheres com 52,9\% e os homens com $47,1 \%$.

A Tabela 1 refere-se à variável "Passei a comprar menos em lojas físicas durante a pandemia"; apresenta um $p$-valor de 0,470 para a hipótese H0 e um p-valor de 0,128 para a hipótese H1, sugerindo que as hipóteses H0 e H1 não devem ser rejeitadas, ou seja, nos cruzamentos dos dados por gênero e faixa etária, não há diferença significativa entre as respostas.

Conforme demonstrado na Tabela 1, observa-se que as compras em lojas físicas diminuíram drasticamente com a pandemia e o isolamento social, sendo que a pesquisa aponta um índice de 72,1\% de concordância, no entanto, esse percentual é menor entre os estudantes universitários de até 19 anos, com 50\%. Esta redução abrupta é suscitada como um dos efeitos graves da pandemia da COVID-19 com relação aos indicadores socioeconômicos, ou seja, a pandemia ultrapassa indicadores de saúde pública (Avelar et al, 2020; IPEA, 2020).

Tabela 1 - Passei a comprar menos em lojas físicas durante a pandemia.

\begin{tabular}{ccccccc}
\hline Escala & Feminino & Masculino & Até 19 & $\mathbf{2 0 / 2 5}$ & $\mathbf{2 6}+$ & Total \\
\hline Concordo & $67,3 \%$ & $77,6 \%$ & $50,0 \%$ & $76,0 \%$ & $77,8 \%$ & $72,1 \%$ \\
\hline Indiferente & $21,8 \%$ & $16,3 \%$ & $38,9 \%$ & $18,0 \%$ & $11,1 \%$ & $19,2 \%$ \\
\hline Discordo & $10,9 \%$ & $6,1 \%$ & $11,1 \%$ & $6,0 \%$ & $11,1 \%$ & $8,7 \%$ \\
\hline Total Geral & $100,0 \%$ & $100,0 \%$ & $100,0 \%$ & $100,0 \%$ & $100,0 \%$ & $100,0 \%$ \\
\hline
\end{tabular}

Fonte: Dados da pesquisa (2020).

A Tabela 2 refere-se à variável "Passei a comprar mais on line durante a pandemia"; apresenta um $p$-valor de 0,786 para a hipótese $\mathrm{H} 0$ e um $p$-valor de 0,015 para a hipótese H1. O teste sugere que a hipótese $\mathrm{H} 0$ não deve ser rejeitada, por outro lado, a hipótese H1 deve ser rejeitada, ou seja, nos cruzamentos dos dados por gênero e faixa etária, há diferença significativa entre as respostas dos estudantes universitários.

Conforme demonstrado na Tabela 2, há um crescimento nas compras on line e isso se justifica devido a diminuição de compras em lojas físicas conforme Tabela 1 . O índice de compras em lojas on line recebe 64,4\% de concordância, se destacando junto aos estudantes universitários acima de 26 anos com 77,8\%, que é corroborado pelo Teste Qui-Quadrado que sugere uma maior associação com os de maior idade que citaram consumir mais on line nesse momento. 
Provavelmente, essa situação tem ocorrido ao desejar receber os produtos em sua casa com mais segurança e conforto contribuindo para o bem-estar de todos em função da pandemia da COVID-19. O comportamento de compras do consumidor voltado para lojas on line não é concentrado em grandes centros urbanos, conforme Chiusoli e Bonfim (2020), consultando consumidores em um município do interior do Paraná com 20 mil habitantes constataram que há um boa receptividade do consumidor para comprar em loja on line.

Chiusoli e Bonfim (2020), caracterizam que mais da metade dos participantes da pesquisa gastam $\mathrm{R} \$ 400,00$ anualmente com compras de uma a três vezes ao ano preferindo pagamento via boleto bancário.

Tabela 2 - Passei a comprar mais on line durante a pandemia.

\begin{tabular}{ccccccc}
\hline Escala & Feminino & Masculino & Até 19 & $\mathbf{2 0 / 2 5}$ & $\mathbf{2 6}+$ & Total \\
\hline Concordo & $61,8 \%$ & $67,3 \%$ & $44,4 \%$ & $62,0 \%$ & $77,8 \%$ & $64,4 \%$ \\
\hline Indiferente & $29,1 \%$ & $26,5 \%$ & $38,9 \%$ & $36,0 \%$ & $11,1 \%$ & $27,9 \%$ \\
\hline Discordo & $9,1 \%$ & $6,1 \%$ & $16,7 \%$ & $2,0 \%$ & $11,1 \%$ & $7,7 \%$ \\
\hline Total Geral & $100,0 \%$ & $100,0 \%$ & $100,0 \%$ & $100,0 \%$ & $100,0 \%$ & $100,0 \%$ \\
\hline
\end{tabular}

Fonte: Dados da pesquisa (2020).

A Tabela 3, refere-se à variável "Durante o isolamento social passei a comprar mais bens não-essenciais"; apresenta um $p$-valor de 0,200 para a hipótese $\mathrm{H} 0$ e um $p$-valor de 0,769 para a hipótese H1. Os resultados do teste estatístico sugerem que as hipóteses H0 e H1 não devem ser rejeitadas, ou seja, nos cruzamentos dos dados por gênero e faixa etária, não há diferença significativa entre as respostas dos estudantes universitários.

Nota-se que, durante a pandemia sendo uma época de crise, com desemprego, produtos com preços em alta, ainda que pouco, uma procura de bens não-essenciais, é citado por $25 \%$ dos estudantes universitários, ou seja, além dos produtos considerados bens essenciais que são produtos de alimentação, saúde e higiene, ainda há demanda para as demais categorias considerados não-essenciais, como o fechamento de escolas e universidades, do comércio em geral e de áreas públicas de lazer, entre outros (Bezerra et al, 2020).

Tabela 3 - Durante o isolamento social passei a comprar mais bens não-essenciais.

\begin{tabular}{ccccccc}
\hline Escala & Feminino & Masculino & Até 19 & $\mathbf{2 0 / 2 5}$ & $\mathbf{2 6}+$ & Total \\
\hline Concordo & $20,0 \%$ & $30,6 \%$ & $22,2 \%$ & $28,0 \%$ & $22,2 \%$ & $25,0 \%$ \\
\hline Indiferente & $40,0 \%$ & $44,9 \%$ & $33,3 \%$ & $42,0 \%$ & $47,2 \%$ & $42,3 \%$ \\
\hline Discordo & $40,0 \%$ & $24,5 \%$ & $44,4 \%$ & $30,0 \%$ & $30,6 \%$ & $32,7 \%$ \\
\hline Total Geral & $100,0 \%$ & $100,0 \%$ & $100,0 \%$ & $100,0 \%$ & $100,0 \%$ & $100,0 \%$ \\
\hline
\end{tabular}

Fonte: Dados da pesquisa (2020).

A Tabela 4 refere-se à variável "Empresa que oferece delivery poderá fazer que eu compre mais dela"; mostra um pvalor de 0,532 para a hipótese $\mathrm{H} 0$ e um $p$-valor de 0,611 para a hipótese H1 sugerindo que as hipóteses H0 e H1 não devem ser rejeitadas, ou seja, nos cruzamentos dos dados por gênero e faixa etária, não há diferença significativa entre as respostas dos estudantes universitários. Essa questão mostra com muita força nas respostas que receber os produtos no conforto da casa é a melhor escolha na situação atual, onde o índice obtido na pesquisa é 85,6\% de concordância.

Esta resposta alinha-se a Vasconcelos e Vasconcelos (2020), quando afirmam que, durante o isolamento social, em tempos de pandemia as empresas se adaptaram em oferecer serviços de delivery de seus produtos que se tornou uma estratégia essencial a atividade comercial. 
Feitosa e Garcia (2016), lembram que o delivery está presente em todas as categorias de aferição de selos (bronze, prata, ouro ou diamante) para lojas virtuais conveniadas ao sistema de avaliação $e$ BIT e consequentemente, é integrante de sistemas de reputação de e-commerce.

Tabela 4 - Empresa que oferece delivery poderá fazer que eu compre mais dela.

\begin{tabular}{ccccccc}
\hline Escala & Feminino & Masculino & Até 19 & $\mathbf{2 0 / 2 5}$ & $\mathbf{2 6}+$ & Total \\
\hline Concordo & $89,1 \%$ & $81,6 \%$ & $88,9 \%$ & $86,0 \%$ & $83,3 \%$ & $85,6 \%$ \\
\hline Indiferente & $9,1 \%$ & $16,3 \%$ & $11,1 \%$ & $14,0 \%$ & $11,1 \%$ & $12,5 \%$ \\
\hline Discordo & $1,8 \%$ & $2,0 \%$ & $0,0 \%$ & $0,0 \%$ & $5,6 \%$ & $1,9 \%$ \\
\hline Total Geral & $100,0 \%$ & $100,0 \%$ & $100,0 \%$ & $100,0 \%$ & $100,0 \%$ & $100,0 \%$ \\
\hline
\end{tabular}

Fonte: Dados da pesquisa (2020).

A Tabela 5 refere-se à variável "Procuro sempre comprar marcas que já comprei anteriormente"; mostra um p-valor de 0,071 para a hipótese H0 e um p-valor de 0,943 para a hipótese H1, sugerindo que as hipóteses H0 e H1 não devem ser rejeitadas, ou seja, nos cruzamentos dos dados por gênero e faixa etária, não há diferença significativa entre as respostas.

Considerando os dados obtidos que ao adquirir um bem ou serviço, optam por marcas já utilizadas por 70,2\% dos estudantes universitários provavelmente, por alguns aspectos como conforto, durabilidade, confiabilidade, uma vez que foi uma experiência de compra já vivenciada. Resultados sugerem que durante esse momento de lockdown, o desejo de preferir um determinado produto torna-se relevante quanto as suas preferências no ato da decisão de consumo (Oliveira Rosa, Casagrande \& Spinelli, 2017).

Tabela 5 - Procuro sempre comprar marcas que já comprei anteriormente.

\begin{tabular}{ccccccc}
\hline Escala & Feminino & Masculino & Até 19 & $\mathbf{2 0 / 2 5}$ & $\mathbf{2 6}+$ & Total \\
\hline Concordo & $61,8 \%$ & $79,6 \%$ & $66,7 \%$ & $70,0 \%$ & $72,2 \%$ & $70,2 \%$ \\
\hline Indiferente & $38,2 \%$ & $18,4 \%$ & $33,3 \%$ & $28,0 \%$ & $27,8 \%$ & $28,8 \%$ \\
\hline Discordo & $0,0 \%$ & $2,0 \%$ & $0,0 \%$ & $2,0 \%$ & $0,0 \%$ & $1,0 \%$ \\
\hline Total Geral & $100,0 \%$ & $100,0 \%$ & $100,0 \%$ & $100,0 \%$ & $100,0 \%$ & $100,0 \%$ \\
\hline
\end{tabular}

Fonte: Dados da pesquisa (2020).

A Tabela 6 refere-se à variável "Durante o isolamento social percebi que as propagandas de produtos aumentaram"; mostra um $p$-valor de 0,490 para a hipótese H0 e um p-valor de 0,531 para a hipótese H1, sugerindo que as hipóteses H0 e H1 não devem ser rejeitadas, ou seja, nos cruzamentos dos dados por gênero e faixa etária, não há diferença significativa entre as respostas dos estudantes universitários.

Essa questão mostra que com o isolamento social, as pessoas tendem a acessar os meios de comunicação, bem como, as redes sociais e dessa forma, percebem propagandas e diversas promoções realizadas pelas empresas, que não deixa de ser uma estratégia para divulgarem seu produto afim de atingir uma quantidade maior de público, uma vez estando "enclausurado", que é reforçado por $75 \%$ de concordância pelos entrevistados.

Assim, verifica-se que empresas que já possuíam sites, no entanto estes eram inicialmente de informação e propaganda, mas tiveram que ser readequados para suportar as vendas virtuais se adaptando com muito esforço a este novo cenário (Maia et al., 2019).

Entre os canais de comunicação google AdWords, e-mail marketing e facebook Maia et al, (2019), ressaltam que, o $e$ mail marketing maior prospecção de clientes, com maior conversão de pedidos de compra e menor taxa de clientes perdidos logo, as empresas devem avaliar e comparar seus canais de comunicação eletrônica com seus clientes. 
Tabela 6 - Durante o isolamento social percebi que as propagandas de produtos aumentaram.

\begin{tabular}{|c|c|c|c|c|c|c|}
\hline Escala & Feminino & Masculino & Até 19 & $\mathbf{2 0} / \mathbf{2 5}$ & $\mathbf{2 6}+$ & Total \\
\hline Concordo & $78,2 \%$ & $71,4 \%$ & $66,7 \%$ & $72,0 \%$ & $83,3 \%$ & $75,0 \%$ \\
\hline Indiferente & $21,8 \%$ & $24,5 \%$ & $33,3 \%$ & $24,0 \%$ & $16,7 \%$ & $23,1 \%$ \\
\hline Discordo & $0,0 \%$ & $4,1 \%$ & $0,0 \%$ & $4,0 \%$ & $0,0 \%$ & $1,9 \%$ \\
\hline Total Geral & $100,0 \%$ & $100,0 \%$ & $100,0 \%$ & $100,0 \%$ & $100,0 \%$ & $100,0 \%$ \\
\hline
\end{tabular}

Fonte: Dados da pesquisa (2020).

A Tabela 7 refere-se a variável "Durante o isolamento social diminuiu a confiabilidade sob higiene de lanchonetes/fastfood"; mostra um p-valor de 0,175 para a hipótese H0 e um $p$-valor de 0,934 para a hipótese H1, sugerindo que nos cruzamentos dos dados por gênero e faixa etária, não há diferença significativa entre as respostas dos estudantes universitários.

Apesar de enfrentar uma pandemia onde o contágio é fácil e o tratamento delicado, verifica-se que entre os estudantes universitários apenas 42,3\% confiam na higiene sob produção de alimentos em lanchonetes/fastfoods, onde deveriam ser rigorosamente verificados pela vigilância afim de manter a saúde e o bem-estar da população.

Tabela 7 - Durante o isolamento social diminuiu a confiabilidade sob higiene de lanchonetes/fastfood.

\begin{tabular}{ccccccc}
\hline Escala & Feminino & Masculino & Até 19 & $\mathbf{2 0 ~ / ~ 2 5}$ & $\mathbf{2 6}+$ & Total \\
\hline Concordo & $38,2 \%$ & $46,9 \%$ & $44,4 \%$ & $42,0 \%$ & $41,7 \%$ & $42,3 \%$ \\
\hline Indiferente & $49,1 \%$ & $53,1 \%$ & $44,4 \%$ & $52,0 \%$ & $52,8 \%$ & $51,0 \%$ \\
\hline Discordo & $12,7 \%$ & $0,0 \%$ & $11,1 \%$ & $6,0 \%$ & $5,6 \%$ & $6,7 \%$ \\
\hline Total Geral & $100,0 \%$ & $100,0 \%$ & $100,0 \%$ & $100,0 \%$ & $100,0 \%$ & $100,0 \%$ \\
\hline
\end{tabular}

Fonte: Dados da pesquisa (2020).

A Tabela 8 refere-se à variável "Importante conhecer o procedimento de higiene dos produtos alimentícios antes de comprar"; mostra um p-valor de 0,391 para a hipótese H0 e um p-valor de 0,213 para a hipótese H1. Diante dos resultados as hipóteses H0 e H1 não devem ser rejeitadas, ou seja, nos cruzamentos dos dados por gênero e faixa etária, não há diferença significativa entre as respostas dos estudantes universitários.

Ao observar os resultados dessa questão 90,4\% concordam que é importante saber os procedimentos de produtos alimentícios que estão prestes a consumir, ou seja, talvez só atender o pedido do cliente não supra a necessidade do mesmo com a confiabilidade do produto, portanto, mostrar ao cliente o procedimento de produção pode ser a forma de conquistar a confiabilidade do cliente transmitindo segurança ao consumir seu produto, e existem várias formas de passar essa segurança, por exemplo: ao pedir um lanche de fastfood por delivery, um simples panfleto mostrando sua produção e ambiente pode ser o suficiente para conquistar o cliente.

Talvez este comportamento de compra dos consumidores estudantes universitários represente uma percepção e um impacto natural ao isolamento social que a pandemia da COVID-19, assim como o stress e a prática de atividades físicas, conforme investigado por Bezerra et al (2020).

Tabela 8 - Importante conhecer o procedimento de higiene dos produtos alimentícios antes de comprar.

\begin{tabular}{ccccccc}
\hline Escala & Feminino & Masculino & Até 19 & $\mathbf{2 0 ~ / ~ 2 5}$ & $\mathbf{2 6}+$ & Total \\
\hline Concordo & $92,7 \%$ & $87,8 \%$ & $88,9 \%$ & $86,0 \%$ & $97,2 \%$ & $90,4 \%$ \\
\hline Indiferente & $7,3 \%$ & $12,2 \%$ & $11,1 \%$ & $14,0 \%$ & $2,8 \%$ & $9,6 \%$ \\
\hline Discordo & $0,0 \%$ & $0,0 \%$ & $0,0 \%$ & $0,0 \%$ & $0,0 \%$ & $0,0 \%$ \\
\hline Total Geral & $100,0 \%$ & $100,0 \%$ & $100,0 \%$ & $100,0 \%$ & $100,0 \%$ & $100,0 \%$ \\
\hline
\end{tabular}

Fonte: Dados da pesquisa (2020). 
A Tabela 9, sintetiza os resultados quanto ao teste Qui-Quadrado, considerando as hipóteses H0 e H1, se deve ser rejeitado ou não-rejeitado ao nível de significância de $1 \%(\mathrm{p} \leq 0,01)$ e $5 \%(\mathrm{p} \leq 0,05)$.

Somente a variável "Passei a comprar mais on line durante a pandemia" na Tabela 2, com p-valor de 0,786 para a hipótese $\mathrm{H} 0$ e $p$-valor de 0,015 para a hipótese H1 apresenta diferença estatística significativa. Logo, quando cruzados os dados por gênero, homens e mulheres tem opiniões bem distintas sobre a variável. O mesmo acontece quando cruzados os dados por faixa etária, universitários até 19 anos tem distinta opinião dos de 20 a 25 anos bem como, os acima de 26 anos.

Por fim, quando cruzados os dados por gênero e faixa etária dos estudantes universitários não apresentaram diferenças estatísticas significativas quanto as variáveis que seguem: "passei a comprar menos em lojas físicas durante a pandemia", "durante o isolamento social passei a comprar mais bem não-essenciais", "empresa que oferece delivery poderá fazer que eu compre mais dela", "procuro sempre comprar marcas que já comprei anteriormente”, "durante o isolamento social percebi que as propagandas de produtos aumentaram", "durante o isolamento social diminuiu a confiabilidade sob higiene de lanchonetes/fastfood", "importante conhecer o procedimento de higiene dos produtos alimentícios antes de comprar". Portanto, na resposta a estas variáveis dos estudantes universitários pesquisados, tanto homens como as mulheres independente da sua faixa etária tem a mesma opinião.

Tabela 9 - Resumo do teste estatístico não-paramétrico: Qui-Quadrado.

\begin{tabular}{ccccc}
\hline Variáveis & $\boldsymbol{p}$-valor & $\begin{array}{c}\text { Teste hipótese } \\
\text { Gênero }\end{array}$ & $\boldsymbol{p}$-valor & $\begin{array}{c}\text { Teste hipótese } \\
\text { Faixa etária }\end{array}$ \\
\hline Tabela 1 & 0,470 & Não rejeitar H0 & 0,128 & Não rejeitar H1 \\
\hline Tabela 2 & 0,786 & Não rejeitar H0 & $0,015^{* *}$ & Rejeitar H1 \\
\hline Tabela 3 & 0,200 & Não rejeitar H0 & 0,769 & Não rejeitar H1 \\
\hline Tabela 4 & 0,532 & Não rejeitar H0 & 0,611 & Não rejeitar H1 \\
\hline Tabela 5 & 0,071 & Não rejeitar H0 & 0,943 & Não rejeitar H1 \\
\hline Tabela 6 & 0,490 & Não rejeitar H0 & 0,531 & Não rejeitar H1 \\
\hline Tabela 7 & 0,175 & Não rejeitar H0 & 0,934 & Não rejeitar H1 \\
\hline Tabela 8 & 0,391 & Não rejeitar H0 & 0,213 & Não rejeitar H1
\end{tabular}

- significativo a $1 \%(\mathrm{p} \leq 0,01) *$ e $5 \%(\mathrm{p} \leq 0,05)^{* *}$ Fonte: Autores $(2020)$.

\section{Considerações Finais}

Com o presente relato de pesquisa que teve como objetivo analisar o comportamento de consumo, hábito e atitudes dos estudantes universitários em momento de lockdown em momento de isolamento social durante a pandemia da COVID-19, entende-se que houve o alcance e respostas diante dos objetivos específicos.

Quanto ao resultado da pesquisa, verifica-se mudança de padrão e comportamento de consumo e permite em tempos de pandemia e que as vendas on line e oferecimento de deliverys são as novas oportunidades para conquistar a confiança desse consumidor.

Considerando os objetivos propostos, os principais achados no momento de isolamento social vivenciado durante a pandemia, tem-se que:

- 72,1\% concordam que passaram a comprar menos em lojas físicas, logo as hipóteses H0 e H1 não devem ser rejeitadas;

- 64,4\% concordam que passaram a comprar mais on line, logo as hipóteses H0 não deve ser rejeitada e H1 deve ser rejeitada; estes resultados apontam que cruzados os dados gênero e faixa etária as opiniões serão distintas sobre a variável; 
- $25 \%$ concordam que com isolamento social compras de bens não-essenciais mesmo com desemprego, produtos com preços em alta, ainda que pouco, uma procura de bens não-essenciais, é citado por $25 \%$ logo, as hipóteses H0 e H1 não devem ser rejeitadas;

- $85,6 \%$ concordam que uma empresa que oferece delivery poderá fazer que eu compre mais dela logo, as hipóteses H0 e H1 não devem ser rejeitadas;

- 70,2\% concordam que procuram sempre comprar marcas que já comprei anteriormente, logo as hipóteses H0 e H1 não devem ser rejeitadas;

- 75,0\% concordam que com o isolamento as propagandas de produtos aumentaram logo, as hipóteses H0 e H1 não devem ser rejeitadas;

- $42,3 \%$ concordam que durante a pandemia, a confiabilidade quanto a higiene de lanchonetes/fastfood diminuiu logo, as hipóteses H0 e H1 não devem ser rejeitadas; e

- 90,4\% concordam que é importante conhecer o procedimento de higienização dos produtos alimentícios antes de comprar logo, as hipóteses H0 e H1 não devem ser rejeitadas.

Bezerra et al (2020), cita pesquisa onde constata-se que os jovens (cearenses) estão mais vulneráveis à contaminação pela COVID-19 por estarem menos isolados que idosos. No entanto, nesta pesquisa com estudantes universitários observa-se que em sua maioria estes jovens estão cientes de sua importante participação no isolamento social imposto por autoridades governamentais.

Isto é evidenciado principalmente, quando passam a comprar mais em lojas on line do que em lojas físicas, consideram o delivery um atrativo para decisão de compra, percebem as propagandas como uma forma de auxiliá-los no processo de compra, questionam a confiabilidade sob a higiene empregada em lanchonetes/fastfoods, reconhecem a importância de conhecer o procedimento de higiene dos produtos alimentícios antes de comprá-los.

Como contribuição este relato de pesquisa demonstra o comportamento dos estudantes universitários frente ao isolamento social e com isso como lidam com as facilidades que a plataforma eletrônica proporciona em relação às compras.

Entretanto, houve algumas limitações da pesquisa, pois se trata de uma amostragem não-probabilística e a análise de ficar restrita ao grupo de estudantes universitários consultados. Desse modo, sugere como trabalhos futuros a realização de estudos mais aprofundados sobre a questão atual para verificar o que acontece após um ano decorrido do isolamento social.

Como estudos futuros pode ser ampliado o escopo do trabalho de modo a levantar mediante outro recorte como estão suas adaptações o momento pós pandemia.

\section{Referências}

Aaker, D. A, Kumar, V. \& Day, G. S. (2001). Pesquisa de Marketing. Ed. Atlas.

Alves, S. M. C., Ramos, E. M. B. \& Delduque, M. C. (2020). Decretação de lockdown pela via judicial: medida (des) necessária? Cadernos de Saúde Pública. 36(6), 1-4.

Avelar, E. A., Ferreira, P. O., Silva, B. N. E. R. \& Ferreira, C. O. (2020). Efeitos da Pandemia de COVID-19 sobre a sustentabilidade econômico-financeira de empresas brasileiras. In: XXIII SEMEAD Seminários em Administração. São Paulo. Anais ... Faculdade de Economia e Administração da Universidade de São Paulo (FEA-USP).

Bezerra, A. C. V., Silva, C. E. M., Soares, F. R. G. \& Silva, J. A. M. (2020). Fatores associados ao comportamento da população durante o isolamento social na pandemia de COVID-19. Ciência \& Saúde Coletiva. 25, 2411-21.

Bueno Neto, P. P., Bueno, M. L. B., Maimoni, M. S. H. \& Masieiro, G.; (2020). One pandemic, many recipes: managing COVID-19 in China, South Korea, Germany, Spain, Brazil and US. XXIII SEMEAD Seminários em Administração. Anais ... Faculdade de Economia e Administração da Universidade de São Paulo (FEA-USP). 1-16.

Chiusoli, C. L. \& Bonfim, R. S. (2020) E-commerce: o comportamento de compras on-line na percepção dos consumidores. Revista Administração em DiálogoRAD. 22 (2), 115-133. 
Research, Society and Development, v. 10, n. 16, e563101624162, 2021

(CC BY 4.0) | ISSN 2525-3409 | DOI: http://dx.doi.org/10.33448/rsd-v10i16.24162

Feitosa, D. L. \& Garcia, L. S. (2016). Sistemas de reputação: um estudo sobre confiança e reputação no comércio eletrônico brasileiro. Revista de Administração Contemporânea. 20(1), 84-105.

Flick, U. (2012). Introdução à metodologia de pesquisa: um guia para iniciante. Penso Editora.

Gil, A. C. (2017). Como elaborar projetos de pesquisa. (6a ed.), Ed. Atlas.

Gimenez, F. A P. (1998). Escolhas estratégica e estilo cognitivo: um estudo com pequenas empresas. Revista de Administração Contemporânea. 2 (1), $27-45$.

Instituto De Pesquisa Econômica Aplicada (IPEA) (2021). Política econômica emergencial orientada para a redução dos impactos da pandemia da COVID-19 no Brasil: medidas fiscais, de provisão de liquidez e de liberação de capital. <https://www.ipea.gov.br/portal/images/stories/PDFs/TDs/td_2576.pdf>. Acesso em: 16 abr. 2021.

Kotler, P. \& Armstrong, G. (2015). Princípios de Marketing. (15a ed.), Pearson Education do Brasil.

Lanchimba, C., Bonilla-Bolaños, A. \$ Díaz-Sánchez, J. P. (2020). A pandemia do Covid-19: cenários teóricos de seus impactos socioeconômicos na América Latina e no Caribe. Brazilian Journal of Political Economy, 40(4), 622-646.

Melito, L. (Brasil) (2020). Sem incentivo, pandemia intensifica dificuldades entre micro e pequenas empresas. 2020. www.brasildefato.com.br.

Maia, B. I., Oliveira, M. A. \& Futami, A. H. (2019). Inovação nos Canais de Comunicação como Forma de Comercialização. Revista de Administração e Negócios da Amazônia. 11(4).

Marconi, M. de A. \& Lakatos, E. M. (2017). Técnicas de pesquisa: planejamento e execução de pesquisas, amostragens e técnicas de pesquisa, elaboração, análise e interpretação de dados. (8a ed.) Ed. Atlas.

Mintzberg, H., Ahlstrand, B. \& Lampel, J (2010). Safári da estratégia: um roteiro pela selva do planejamento estratégico. Bookman.

Oliveira Rosa, R., Casagranda, Y. G. \& Spinelli, F. E. (2017). A importância do marketing digital utilizando a influência do comportamento do consumidor. Revista de Tecnologia Aplicada. 6(2).

Rodrigues, D. (2016). Alinhamento interno de estratégias emergentes: um estudo de caso em operadora de telecomunicações. Dissertação (mestrado), Universidade de São Paulo.

Siegel, S. E. \& Castellan Junior, N. J. (2017). Estatística Não-Paramétrica para as Ciências do Comportamento. Artmed-Bookman.

Vasconcelos, P. S. \& Vasconcelos, P. E. A. (2020). Desafios da Estratégia Empresarial: antes, durante e após a pandemia de 2020. Revista Interdisciplinar de Direito. 18(1), 163-182 